\title{
Master of Agriculture Education and Strategy of Rural Revitalization in China
}

\author{
Wen $\mathrm{Bao}^{1, *}$ and Jing $\mathrm{Li}^{2}$ \\ ${ }^{1}$ Management School, Chengdu University of Information Technology, Sichuan Province, China, 610103 \\ ${ }^{2}$ Management School, Chengdu University of Information Technology, Sichuan Province, China, 610103 \\ *Corresponding author. Email: baowen@cuit.edu.cn
}

\begin{abstract}
It is widely acknowledged that quality Master of Agriculture education is very important to modern agricultural innovation and the strategy of rural revitalization in China. To be more responding to increasing demand for fast delivery of perishable produce to market and traceability from farm to fork, expand agro-food industries, and remove barriers to rural revitalization, rural China must expand knowledge and expertise in science and technology. Building human capital through Master of Agriculture education is a way to empower rural China to take advantage of its strengths.
\end{abstract}

Keywords: Master of Agriculture education, Modern agricultural innovation, Strategy of rural revitalization, China.

\section{ROLE OF MASTER OF AGRICULTURE EDUCATION IN THE STRATEGY OF RURAL REVITALLIZATION}

Over the last decade Chinese government has increasingly recognized the need to reshape Master of Agriculture education to meet the changing needs of the strategy of rural revitalization. There is a strong appetite for change but a need for a better understanding of the challenges that universities face in transforming into institutions that can be more dynamic and responsive, especially to the needs of modern agricultural innovation and meet the rapidly growing demand for rural revitalization.

\subsection{The Importance of Master of Agriculture Education in rural revitalization}

Universities engaged in Master of Agriculture education are part of an Agricultural Education System that includes universities or departments that are specialized in agriculture and universities or departments that are not specialized in agriculture but deliver education and research that is directly part of agricultural education and research or relevant to it.

The supply of highly effective human resources profoundly contributes to facilitate agroindustrialization development and modernization of rural areas in China.[1] Universities contribute by far the greatest numbers of Master's-level workers in Chinese labor forces. The workers of Master of Agriculture graduating from universities then influence the quality of the rest of the workforce, through the training that they provide to others---in primary and secondary schools, in agricultural training colleges, in technical and vocational education training schools, in public sector jobs, in civil society, and in the private sector.

\subsection{The Importance of Master of Agriculture Education in Rural Economic Transformation}

Master of Agriculture education plays a very important role in promoting economic transformation in rural China. Even though the majority of workers in the countryside will never step foot on a university campus, they are still likely to receive training from and be influenced by Master of Agriculture in the form of primary or secondary school teachers, agricultural extension programs, agricultural training, vocational and extension schools, civil servant and officials of rural areas. Through their diffuse effect on workforce quality, Master of Agriculture education exert a profound effect on the pace of rural development.

Even with rapid economic diversification and nonfarm employment expansion, the central government 
reconfirms the foundational role of agriculture in enabling and driving economic diversification and transformation. China rural grass-roots governance is the important issue in economics field.[2] Because the economy of the countryside strongly depend on agriculture, the central government may contribute to achieving their its growth and governance objectives by strengthening its higher education capacity related to Master of Agriculture education.

\subsection{Role of Master of Agriculture Education in Agricultural Innovation System}

Master of Agriculture education is part of agricultural innovation ecosystem that includes agricultural extension systems, research and development (R\&D) institutes, agricultural policy research institutes, regional agricultural organizations and agricultural innovation hubs, as well as farmers and agribusinesses.

The quality of Master of Agriculture education influences the effectiveness of workers in agricultural innovation ecosystem. The quality of research undertaken by a Master of Agriculture may usefully guide and orient the activities of the agricultural innovation ecosystem. For example, research has documented how modern agricultural development is raising the demand for labor-saving agricultural technologies in some areas where labor wages are rising rapidly, and land-saving technologies in other areas where land scarcity is becoming an acute problem. [3] Their research on how agricultural land and labor prices are evolving in different parts of our country can usefully orient public agricultural $R \& D$ programs toward labor-saving or labor-saving forms of technical innovation appropriate to specific areas. Some initiatives can help coordinate the activities of agricultural R\&D units, extension systems.[4] And universities have a major role to play in anticipating and coordinating with the private sector to ensure that the skills sets of Master of Agriculture are meeting the demands of the rapidly evolving firms in modern agricultural development.

The benefit of system perspectives is gaining momentum for reform efforts to improve Master of Agriculture education systems in China, particularly for creating environments that enable innovation. An innovation system is a network of organizations, enterprises, and individuals focused on bringing new products, new processes, and new forms of organization into economic use, together with the institutions and policies that affect their behavior and performance. [5] This system includes informal as well as formal rules and looks more like a spider web of related individuals and organizations, all of whom contribute something to the application of new or existing information and knowledge.

\section{TRENDS INFLUENCING THE DESIGN OF MASTER OF AGRICULTURE EDUCATION IN CHINA}

\subsection{Demographic Change Driving an Increase in Demand for Master of Agriculture Education}

China is the biggest developing country of the world where the rural population of under-20s is continuing to decrease. Every year, roughly 10 million young Chinese are entering universities. In combination the factor of the national strategy of rural revitalization have resulted in increases in demand for Master of Agriculture enrollment. The demand for Master of Agriculture education in China will rise tremendously over the next decade.

\subsection{Structural Evolution of Agricultural Value Chains - Driving Demand for Downstream Job Skills}

Over the next ten years, the agricultural system of China will continue its transition along a similar trajectory as experienced in developed countries. Generation of employment and valuation addition will shift from farms to off-farm agro-food industries such as distribution, packaging, processing, finance, technology development and dissemination, insurance, technical analysis and later to food services.

The skills required for success in these businesses are diverse and involve soft skills as well as technical and problem-solving skills. Master of Agriculture education in China needs to position itself to effectively train those who will be providing the training to these millions of workers in agri-food systems of China.

\subsection{Technological Revolution - Driving Demand for Skills in Application of Digital Technology and Biotechnology to Agricultural Value Chains}

The fourth industrial revolution driven by digitization and parallel advances in automation, precision technology, geographic information systems (GIS) is rapidly changing the way agricultural value chains operate. The agricultural sector is a late adopter of digital technology compared to other sectors but the scope for its application is enormous. Improved weather modeling, GIS, advanced capacity to analyze climate, agricultural production mega-data and mobile technology can now provide widespread access to high accuracy early warning and production advice; blockchain and mobile connectivity can respond to increasing demand for fast delivery of perishable produce to market and traceability from farm to fork; and automation and precision agriculture can 
dramatically improve the efficiency of water and input use. Human capital development needs to keep pace with technology.

\subsection{Urbanization and Rising Incomes-Driving Demand for Better Nutritional Skills}

Over the next ten years, China will continue experience a dietary transformation driven by rising incomes and urbanization. In light of these trends, Chinese diets are already changing toward processed foods. Chinese dietary transformation is causing an increased prevalence of health conditions noted in "Western diets" such as obesity and cardio-vascular disease.[6] Food science and technology and nutritional expertise will have an increasingly critical role to play. However, Master of Agriculture education in Chinese universities is insufficient, not to mention nutrition education.

\subsection{Climate Change - Driving Demand for Skills in Agricultural Disaster Prevention and Mitigation Technology}

Climate change and variability is causing major challenges for maintaining agricultural productivity. These challenges create an urgent need for China to develop and implement agricultural, water and land management practices that promote sustainable productivity and resilience. Effective responses to climate-related threats will require significant investment in growing capacities of individuals and institutions within Chinese education and research systems.[7] So far, almost all strategies for addressing climate change, sustainability and resilience issues are being paid more and more attention to. Master of Agriculture education in Chinese universities will be an important factor in producing the necessary research for climate change response and in attracting and training professionals and workers in livestock and crop science and agronomy, food science and technology, agricultural economics, and management who will have the incentives to generate sustainable and resilient responses to the region's challenges associated with climate change.

\subsection{Land and Biodiversity Degradation - Driving Demand for Skills in Ecosystem Management}

When land is degraded, soil carbon can be released into the atmosphere, along with nitrous oxide. To solve this problem will require major new investment in agricultural soil scientists, agronomists, agricultural economists, and sustainability oriented land management departments. There is an urgent need to foster more Master of Agriculture now that will produce the next generation of Chinese scientists incentivized to work in rural areas to solve the land degradation problem. The amounts of learning achieved in Master of Agriculture education should also be broadened to investigating biotic and abiotic stressors, which are both likely to become more prevalent and serious with greater climate variability. Master of Agriculture education in Chinese universities must address the question of how China can develop the capacity to anticipate and respond effectively to these challenges.

\section{CORE CHALLENGES TO DEVELOPMENT OF MASTER OF AGRICULTURE EDUCATION IN CHINA}

\subsection{Teaching}

\subsubsection{Designing More Relevant Courses}

There is a consensus among alumni and agribusiness companies that current Master of Agriculture education tends to be overly theoretical, unapplied, and/or outdated. In the universities of China, these are well recognized challenges and efforts have been made to respond to them.[8] Nevertheless, the systematic use of analytical tools to assess agri-food sector skills needs and feedback into the design of curricula and research programs is inadequate. Tracer studies that track where students are employed when they graduate and occupational studies to provide a detailed understanding of the task involved in specific jobs would greatly inform efforts to increase the relevance of Master of Agriculture education but such a rigorous approach appears to be uncommon.

\subsubsection{Curricula Revision}

If teaching is to improve in Master of Agriculture education, it is essential that managers and teachers be mindful of the bureaucratic and personnel constraints that stand in the way of curricular reform. One constraint is the bureaucratic cycle of curricular change. Curricula of most of the universities are reviewed every 3-5 years. In general, universities do not make official revisions in curricula outside this cycle, which is mandated in most cases by the government ministry or agency that regulates Master of Agriculture education. Another constraint on curricular reform arises from heavy faculty workloads and the absence of incentives to change. Curricular revision is nearly always done by the faculty members who teach the courses under review, who already have a heavy teaching load and view curricular revision as additional work with little benefit to them. [9] 


\subsubsection{Providing Experiential Learning}

Inadequate practical internship opportunities are the major reason for weak university-private sector linkages. There have two types of work-integrated learning: internships and fieldwork. Both should be expanded but, to make the expansion worthwhile, the quality of the work-integrated learning programs must be improved. In Chinese universities, there is need for stronger relationships with businesses, better design of student work programs, and more funding for supervision and program support. In China, the use of internships by businesses as a means of employee recruitment is not widespread, and managers tend to regard internships as a bother and unjustified expense. Consequently, universities have difficulty finding an adequate number of internship slots for their students. A related problem is that companies that accept interns tend to relegate them to the status of observers and assign those tasks peripheral to core business functions.

\subsection{Research}

The staff incentive and support system is not conducive to maintaining a long-term team of senior researchers in Master of Agriculture education. There is a need for stronger incentives and support systems to build strong research teams and portfolios. The proportion of academic staff that hold senior rank is far less than the proportion that hold junior or middle rank in many teams of Master of Agriculture education in Chinese universities, and efforts to increase the relative size of the senior staff are often unsuccessful. This imbalance has important implications for the research productivity of universities since the pursuit of promotion through a series of well-defined steps is an important motivator of research activity and scientific publication. Instead of building their research portfolios for promotion, many junior academic staff teaches the required load of courses without devoting much time and serious effort to research.

\section{RECOMMENDATIONS}

\subsection{National Level Reforms}

\subsubsection{Strategy}

A national strategy for building Master of Agriculture education or update of existing strategies, prepared in consultation with responsible public agencies, universities and the private sector, would provide useful direction to these institutions and a united approach going forward. The strategy could for example define: (i) objectives of reform that meet the need of modern agricultural innovation and strategy of rural revitalization; (ii) vision for necessary changes in the thematic scope of Master of Agriculture education to respond to changing knowledge and skills needs; (iii) financial strategy; and (iv)regulatory strategy.

\subsubsection{Thematic Scope}

As part of the above strategy, in cooperation with the private sector, public sector and universities, the Ministry of Education should consider changes in thematic scope of Master of Agriculture education including to respond to skills needs in the areas of (i) agribusiness and food industry management; (ii) human health and nutrition; (iii) climate change, agriculture and ecosystem management; (iv) agricultural risk management tools; (v) digital technology in agri-food value chains, with a strong focus on broadening Master of Agriculture education to address issues and interactions across markets (agricultural, environmental, financial and risk markets), along value chains, throughout ecosystems and across disciplines.

\subsection{Management Reforms}

\subsubsection{Incentives for Staff}

A system of individual accountability would help to motivate member of academic and nonacademic staff to play their part transforming Master of Agriculture education. Universities control the salary levels of their staff, salary increases, allocation of discretionary funding for bonuses, skill upgrading, conference travel, or sabbaticals should be tied to performance with reference to the annual work plan. [10]

\subsubsection{Relevance Enhancement in Teaching and Learning}

For a university to instill a new mindset, new course content, and new pedagogy, it is necessary to train teachers, administrators, and support staff on how to do it and to make Master of Agriculture educational resources available to assist them. [11] First, however, it will be important to gather and analyze data on the knowledge and skills that are needed by employers and entrepreneurs.

\subsubsection{Relevance Enhancement in Research and Extension}

Universities should identify one or more of their most productive senior researchers of Master of Agriculture education to lead periodic research workshops and to serve as mentors to junior researchers. This approach avoids costly transportation and lodging expenses for presenters and participants while complementing a broader strategy of transforming the most productive and innovative faculty members into champions of change within the internal culture of Master of Agriculture education. 


\section{CONCLUSION}

The strategy of rural revitalization is of great significance to the success of the modernization of agricultural and rural areas in China. The reform of Master of Agriculture education must focus on the organic integration of theory and practice, pay attention to the in-depth theoretical exposition and vivid typical cases, and train new agricultural producer, managers, entrepreneurs and rural builders who understand agriculture and love the countryside. Under the premise of clear strategic guidance, we suggested establish a complete management system suitable for the Master of Agriculture education, regulate it, and ensure that strong measures are taken in all aspects to ensure the quality of Master of Agriculture education.

\section{ACKNOWLEDGMENTS}

The authors gratefully acknowledges the financial contribution to this study from research project of the Working Committee on Agriculture and Forestry of the Chinese Institute of Degree and Graduate Education (No.2021-NLZX-YB39)

\section{REFERENCES}

[1] W. Bao, G.J. Chen, CSR and agro-industrialization development in China - The case of Fushun County, Sichuan Province, in: Proceedings of the 2nd Euro-Asia Conference on Environment and Corporate Social Responsibility: Technological Innovation and Management Section, Wissenschaftlicher Verlag Berlin, Bangkok, Thailand, 2007, pp. 113-116.

[2] R. Birnbaum, The Cybernetic Institution: Toward an Integration of Governance Theories, Higher Education 18 (2) (1989) 239-53. DOI: https://doi.org/10.1007/3447084

[3] A.Lam, Tacit Knowledge, Organizational Learning and Societal Institutions: An Integrated Framework, Organization Studies 21 (3) (2010) 487-513. DOI: https://doi.org/10.1177/0170840600213001

[4] S. Hélie, R. Sun, Incubation, Insight, and Creative Problem Solving: A Unified Theory and a
Connectionist Model, Psychological Review 117 (3) (2010) 994-1024. DOI: https://doi.org/10.1037/a0019532

[5] S.Freeman, S. L. Eddy, M. McDonough, M. K. Smith, N. Okoroafor, H. Jordt, and M. P. Wenderoth, Active Learning Increases Student Performance in Science, Engineering, and Mathematics, Proceedings of the National Academy of Sciences 111 (23) (2014) 8410-15. DOI: https://doi.org/10.1073/pnas.1319030111

[6] R.H. Linton, A. Nutsch, D. Mcswane, J. Kastner, T. Bhatt, S. Hodge, K. Getty, D. Maier, C. Kastner, A. Chaturvedi, Use of a Stakeholder-Driven DACUM Process to Define Knowledge Areas for Food Protection and Defense, Journal of Homeland Security and Emergency Management 8 (2) (2011) 1-21. DOI: https://doi.org/10.2202/15477355.1768

[7] D.J. Teece, Managing the University: Why 'Organized Anarchy' Is Unacceptable in the Age of Massive Open Online Courses, Strategic Organization 16 (1) (2018) 92-102. DOI: https://doi.org/10.1177/1476127017732760

[8] L. Deslauriers, E. Schelew, and C. Wieman, Improved Learning in a Large-Enrollment Physics Class, Science 862 (2011) 862-64. DOI: https://doi.org/10.1126/science.1201783

[9] L.A. Simon, J.D. Haygood, C.L. Akers, D.L. Doerfert, C.S. Davis, Master's Level Agricultural Communications Curriculum: A National Delphi Study, Journal of Agricultural Education 46 (3) (2005) 56- $69 . \quad$ DOI: https://doi.org/10.5032/jae.2005.03056

[10]E. Gerrish, The Impact of Performance Management on Performance in Public Organizations: A Meta-Analysis, Public Administration Review 76 (1) (2016) 48-66. DOI: https://doi.org/10.1111/puar.12433.48

[11]M.A. Cohen, J.G. March,J.P. Olsen, A Garbage Can Model of Organizational Choice, Administrative Science Quarterly 17 (1) (1972) 125. DOI: https://doi.org/10.2307/2392088 